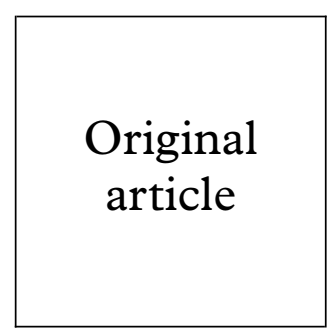

\title{
Polymerase chain reaction detection of Haemophilus ducreyi DNA
}

\author{
D J Roesel, L Gwanzura, P R Mason, M Joffe, D A Katzenstein
}

Objectives: To develop a polymerase chain reaction (PCR) method to detect Haemophilus ducreyi DNA in cultured isolates and clinical material.

Methods: Primers specific to the $H$ ducreyi 16s rRNA gene were synthesised. PCR conditions were optimised and products were verified by restriction endonuclease digestion and agarose gel electrophoresis.

Results: The method was able to detect all $28 \mathrm{H}$ ducreyi strains tested; specificity was demonstrated using lysates of 12 related organisms. Applied to clinical samples from genital ulcer swabs obtained in Harare, Zimbabwe, $H$ ducreyi DNA was detected in repeated assays in 35 clinical samples.

Conclusion: PCR amplification using primers from the 16s rRNA gene may be a useful alternative to culture for the detection of $H$ ducreyi and the diagnosis of chancroid.

(Sex Transm Inf 1998;74:63-65)

Keywords: chancroid; Haemophilus ducreyi; polymerase chain reaction

\section{Introduction}

Haemophilus ducreyi, the causative agent of chancroid, is difficult to detect using traditional methods; the sensitivity of culture may be less than $50 \%$ in endemic regions..$^{1-3}$ We describe a simple method for the diagnosis of chancroid from genital ulcer swabs by polymerase chain reaction (PCR) amplification of a unique fragment of the 16s rRNA gene of $H$ ducreyi.

\section{Materials and methods}

Three regions of the 16s rRNA gene were selected as targets for PCR, the basis of their unique sequence homology in $H$ ducreyi. These sequences correspond to one upstream and two overlapping downstream primers. Primer locations, sequences, and corresponding PCR product sizes are shown in figure 1 . Nucleotide sequences for the 16s rRNA gene of $H$ ducreyi and related species (Pasteurella haemolyticum and $P$ multocida) were obtained from Genbank, and primers were tested for uniqueness against all Genbank DNA sequences using the IntelliGenetics " Genalign" program.

PCR amplification was initially carried out on DNA extracted from cultures of different $H$ ducreyi strains obtained from the University of California, San Francisco and the University of Alberta. Single colonies were selected from culture plates and resuspended in $1.0 \mathrm{ml}$ of sterile saline. Cells were pelleted in a microfuge, the supernatant removed, and the samples washed once with normal saline and TE buffer (100 mM TRIS, $500 \mu \mathrm{M}$ EDTA, pH 8.0). Samples were repelleted, suspended in $200 \mu \mathrm{l}$ of sterile distilled water, and lysed by heating for 10 minutes at $95^{\circ} \mathrm{C}$. The DNA content was quantified by spectrophotometry, and concentrations adjusted to $2 \mathrm{ng} / \mathrm{ml}$. For a positive control, DNA from $H$ ducreyi type strain CIP542 (ATCC 33940) was purified using QIAamp Tissue Kit (QIAGEN, Chatsworth, CA, USA) according to the manufacturer's instructions.

DNA amplification was performed twice on each sample, once using primers 1 and 2, and once using primers 1 and 3 . Each reaction mixture had a total volume of $100 \mu \mathrm{l}$, made up of $10 \mu \mathrm{l}$ of cell lysate (20 pg DNA), $50 \mathrm{pmol}$ of each primer, $50 \mathrm{pmol}$ of each deoxynucleotide triphosphate, and $1 \mathrm{U}$ of Taq polymerase (Perkins-Elmer, Foster City, CA, USA) in a buffer containing $50 \mathrm{mM} \mathrm{KCl}, 10 \mathrm{mM}$ TRIS, $3.5 \mathrm{mM} \mathrm{MgCl}{ }_{2}$ and $1 \%$ gelatin. Forty amplification cycles were performed using an an automated thermocycler: denaturing at $95^{\circ} \mathrm{C}$ for 30 minutes, annealing at $47^{\circ} \mathrm{C}$ for 30 minutes, and elongating at $72^{\circ} \mathrm{C}$ for 80 minutes. A negative control containing no DNA and two positive controls containing $10 \mathrm{pg}$ and $1 \mathrm{pg}$ of purified CIP542 DNA were included in each run. Contamination was minimised by geographically separating DNA extraction, reaction mix preparation, and PCR product analysis.

Twenty $\mu 1$ of each amplified PCR product were analysed by electrophoresis in a 3\% agarose gel containing $0.05 \mathrm{mg} / \mathrm{ml}$ ethidium bromide, and visualised by ultraviolet transillumination

The specificity of the PCR assay was assessed using pure cultures of bacteria commonly found in genital ulcers or sharing a high degree of rRNA sequence homology with $H$ ducreyi. ${ }^{45}$ The following were obtained from the American Type Culture Collection; Escherichia coli (ATCC 47015), Haemophilus influenzae (33391), Haemophilus parahaemolyticum (10014), Pasteurella haemolytica (33396), Pasteurella multocida (43137), Proteus mirabilis (29857), and Treponema pallidum (27087). Clinical isolates of Bacteroides fragilis, Klebsiella pneumoniae, Neisseria gonorrhoeae, Staphylococcus aureus, and Streptococcus agalactiae were 
obtained from the microbiology laboratory at Stanford University Medical Center. Organisms were tested following the same protocol described above.

Clinical material was obtained from men presenting to municipal STD clinics in Harare, Zimbabwe with a complaint of genital ulcer. Using cotton tipped swabs, samples were collected from the base of the ulcers, regardless of the degree of clinical suspicion of chancroid. Unlinked samples submitted to the diagnostic laboratory from 74 men were used for $\mathrm{H}$ ducreyi PCR. The swabs were placed in $2 \mathrm{ml}$ of sterile saline and vortexed; $1 \mathrm{ml}$ of the resulting suspension was transferred to microfuge tubes for centrifugation. The resulting pellet was washed, resuspended in water, and lysed at $95^{\circ} \mathrm{C}$ as previously described. Cell lysates were divided in two, with half of each sample analysed on site in Harare and the remainder stored at $-20^{\circ} \mathrm{C}$ for repeat analysis at Stanford. PCR amplifications were carried out in each

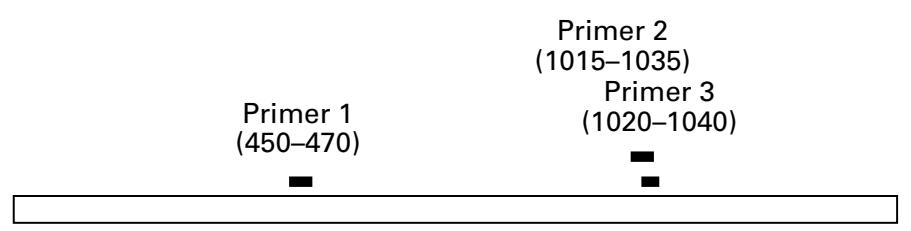

16s rRNA

$585 \mathrm{bp}$ $590 \mathrm{bp}$

\section{Primer 1 5' -AGGCAGTTTGTTAATAGCA- 3' \\ Primer 2 5'-ATAGAAGAACTCAGAGATGA- 3' \\ Primer 3 5'-AGAACTCAGAGATGAGTTTG -3'}

Figure 1 Sequences of oligonucleotide primers and physical map of their locations along Figure 1 Sequences of oligonucleotide primers and physical map of their locations along
the $16 \mathrm{~s}$ rRNA gene. Shaded bands represent the relative sizes of the amplification products. Nucleotide positions correspond to those of Dewhirst et al. ${ }^{4}$
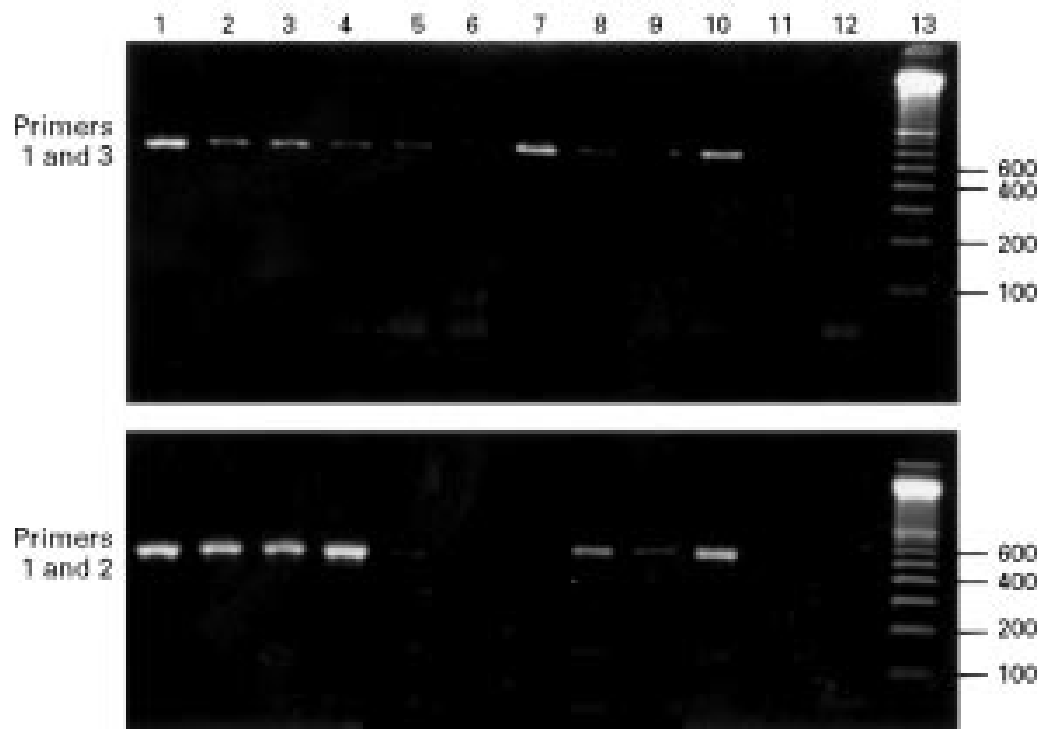

Figure 2 Specificity of primer sets for amplification of $16 s \mathrm{rRNA}$ gene sequence in $H$ ducreyi . Lanes 1-4: 585-590 bp amplification products using 20 pg DNA from H ducreyi ATCC type strain and isolates from San Francisco, Kenya, and Singapore respectively. Lanes 5-7: amplification products using $20 \mathrm{ng} D N A$ from pure cultures of $N$ gonorrhoeae, $P$ mirabilis, and $H$ influenzae respectively. Lanes 8-11: amplification products from Zimbabwean clinical samples. Lane 12: negative control. Lane 13: molecular weight marker. location as described above, using $25 \mu \mathrm{l}$ of lysate in each reaction mix.

Testing of PCR products by restriction fragment analysis was performed on all positive reactions run at Stanford. PCR product, $15 \mu \mathrm{l}$, was incubated separately with Hinc II and Rsa I endonucleases (New England Biolabs) for 1 hour at $37^{\circ} \mathrm{C}$ in $30 \mu \mathrm{l}$ total volume, following manufacturer's recommendations. Restriction fragments were visualised by ethidium bromide-agarose gel electrophoresis and ultraviolet transillumination.

\section{Results}

PCR amplification of $H$ ducreyi type strain CIP542 yields a 585 base pair (bp) product with primers 1 and 2, and a 590 bp product with primers 1 and 3 . The smallest amount of DNA able to generate a visible fragment on an ethidium bromide stained agarose gel was 0.1 pg (roughly 10-100 organisms). Testing of 28 strains of $H$ ducreyi isolated from different locations in Africa, Asia, Europe, and North America produced the expected fragments in every case; all of the PCR products gave the appropriate restriction fragments (fig 2).

Three of the bacterial species used to assess the specificity of the PCR assay also generated a 580-600 bp product: $H$ influenzae, $P$ mirabilis, and $N$ gonorrhoeae. A visible amplification product was only observed when using 1000 times the amount of DNA required to amplify $H$ ducreyi. Moreover, digestion of these PCR products with Hinc II and Rsa I produced different fragments from those seen with $H$ ducreyi (data not shown).

$H$ ducreyi DNA was amplified in clinical samples, with no significant difference in detection rates in samples containing visible blood or pus $\left(\chi^{2}\right.$ test, $\left.\mathrm{p}=0.44\right)$. Results obtained in Harare using PCR alone were consistent with results obtained at Stanford. In Harare, 38 of 74 (51\%) of samples detected $H$ ducreyi with at least one set of PCR primers; of these, $35(92 \%)$ were confirmed positive at Stanford by repeat PCR and restriction analysis. (Two of the three discrepant samples failed to give the appropriate restriction pattern with Rsa I, the third did not produce fragments with either enzyme.) All of the negative samples remained negative upon retesting.

\section{Discussion}

Historically, the diagnosis of chancroid has been problematic because of the unreliability of clinical diagnosis and the difficulty of culture methods for $H$ ducreyi. ${ }^{1-3} 6$ PCR is an attractive alternative to culture which is not hindered by contaminating organisms, can be used to test large numbers of fresh or frozen samples, and has been shown to be feasible in developing countries. ${ }^{7}$ Recently, Chui et al developed a PCR assay for $H$ ducreyi using broad range (nonspecific) primers to the 16s rRNA gene and a specific radioactive oligonucleotide probe. ${ }^{8} \mathrm{By}$ contrast, we have developed an approach using specific primers, thus eliminating the need for DNA hybridisation and radionucleotides, making the technique more accessible for less equipped laboratories. The technique amplified 
all $H$ ducreyi strains tested, worked in crude clinical material, and gave consistent results in Zimbabwe and the United States. The detection of $H$ ducreyi DNA in $47 \%$ of genital ulcer samples is similar to reported frequencies of detection of chancroid by Gram stain, culture, and PCR in other studies in Africa. ${ }^{9}$ We feel this is a promising technique for use in developing countries which warrants rigorous assessment of sensitivity and specificity in comparison with current diagnostic methods.

This work was supported in part by a grant from the Stanford Traveling Scholars Program and the NIH, NIAID through the Preparation for AIDS/HIV Vaccine Evaluation (PAVE) A 33868-02. We are indebted to William Albritton at the University of Alberta and Geoffrey Brooks at the UCSF Division of Laboratory Medicine for use of their isolates of Haemophilus ducreyi. We gratefully acknowledge the contributions and assistance of Stanley ris, Sheryl Ronald, and Mark Winters.
1 Albritton, W L. Biology of Haemophilus ducreyi. Microbiol Rev 198;53:377-89.

2 Dylewski J, Nsanze H, Maitha G, Ronald AR. Laboratory diagnosis of Haemophilus ducreyi: sensitivity of culture media. Diagn Microbiol Infect Dis 1986;11:72-6.

3 Johnson SR, Martin DH, Cammarata C, Morse SA. Development of a polymerase chain reaction assay for the detection of Haemophilus ducreyi. Sex Transm Dis 1994;21:13 23.

4 Dewhirst FE, Paster BJ, Olsen I, Fraser GJ. Phylogeny of 54 representative strains in the family Pasteurellaceae as determined by comparison of $16 \mathrm{~S}$ rRNA sequences. $\mathcal{F ~} \mathrm{Bac}-$ teriol 1992;174:2002-13.

5 Chapel T, Brown WJ, Jeffries C, Stewart JA. The microbial flora of penile ulcerations. F Infect Dis 1978;137:50-6.

6 Dangor Y, Ballard RC, da L Exposto F, Fehler G, Miller SD, Dangor Y, Ballard RC, da L Exposto F, Fehler G, Miller SD,
Koornhof HJ. Accuracy of clinical diagnosis of genital ulcer Koornhof HJ. Accuracy of clinical diagn
disease. Sex Transm Dis 1990;17:184-9.

7 Harris E, Lopez M, Arevalo J, et al. Short courses on DNA detection and amplification in Central and South America: the democratization of molecular biology. Biochem Educ1993;21:8-12.

8 Chui L, Albritton WL, Paster B, Maclean I, Marusky R. Development of the polymerase chain reaction for the diagnosis of chancroid. F Clin Microbiol 1993;31:659-63.

9 West B, Wilson SM, Changalucha J, et al. Simplified PCR for detection of Haemophilus ducreyi and diagnosis of chancroid. F Clin Microbiol 1995;33:787-90.

\section{Historical vignette}

\section{A case history}

The following was recorded by Daniel Turner in his Practical Dissertation on the Venereal Disease, published in 1737:

"A Poor Fellow, recommended to me as an Object of Charity by an Apothecary, made complaint that by lifting up a great Weight, he had got the Disease called the Running of the Reins. I examined the Parts, and found his Linen pretty much stain'd with a yellow Matter; his Urine, on coming out and just after he had done making it, gave him great Disturbance. Perceiving me smiling at this Evasion, he asked me if it were not possible to get a Running by a Strain? I answered that it might be possible in some weakly People; who may let go their Seed upon every slight Occasion, especially in hard straining upon the Stool; but that it must not be such a one as his.

To try him further, I told him if this was not from a Clap I should not pretend to cure him, and advised him to apply elsewhere; upon which he said that about a Fortnight before, it was his Misfortune, being in Drink, to be picked up in the Streets by a Woman, who carried him to a Gin-shop; where he merely touched her labia Pudendorum with his Virga, and for fear of infection withdrew immediately without emission, thinking it impossible that he could thus be injured.

Upon this Acknowledgment, and the Apothecary promising to let him have what I prescribed, I wrote for him as follows [a mixture of Jalap, American Chestnut, astringents and demulcents]. Whilst he was prosecuting this Method, and got himself almost well, his Wife began to complain in like manner; and in a great frighthe came to me one Morning, begging I would see her, or he was undone, she having received the Infection, as he supposed, before he came to me. I asked him jestingly if she too had been lifting some heavy Burden; he replied he was convinced of the Nature of his Disease, as well as of his Wickedness, in abusing a careful and industrious Woman; but she had told him she would come for my opinion.

Accordingly, the same Day she brought a Clout [a piece of cloth] to show me, which she had just taken from her Body. I ask'd her if she had ever had the Whites? She said yes, but they were not of this Colour, nor had she that Heat and Smarting in her water. Besides, she told me that Matters were not right at Home, for her Husband, she was sure, had been taking Physick privately, which he had got from someone unknown to her. Perceiving her to be a Woman of great Spirit, I did all I could to moderate Matters and take off her resentment; telling her that her Body was in an ill state, having lately lain in, so the Flux was sharper than ordinary, but I doubted not quickly to mend her Blood, by a little Purging, and free her from her complaint. Accordingly, I prescribed the same remedy for her in a smaller Dose, which within a few Days lessen'd the Running and took off the Disturbance from her water; when the whole was consumed she got perfectly free of the Distemper On later Enquiry from the Apothecary I understand that both of them have continued well ever since." 